Veritas E Scientia

Vol. 9. N ${ }^{\circ} 1$

Enero - Junio del 2020

ISSN Edición Online: 2617-0639

https://doi.org/10.47796/ves.v9i1.276

\title{
PRINCIPALES FACTORES DE INEFICACIA DE NORMA PROCESAL PENAL QUE FACULTA SOLICITAR COMO PRUEBA ANTICIPADA DECLARACION DE VICTIMAS DEL DELITO INDEMNIDAD SEXUAL, TACNA - 2017
}

\author{
MAIN FACTORS OF INEFFECTIVENESS OF THE CRIMINAL PROCEDURE STANDARD THAT IT HAS \\ TO REQUEST AS AN ADVANCE PROOF STATEMENT OF VICTIMS OF THE CRIME OF SEXUAL \\ INDEMNITY, TACNA - 2017
}

Henry Douglas, Aro Mamani ${ }^{1}$

Hugo Heriberto Soza Mesta ${ }^{2}$

Aceptado: $17 / 06 / 2019$

Publicado online:10/07/2020

\begin{abstract}
RESUMEN
Investigación desarrollada con el motivo de conocer cuáles son esos principales factores que vuelven ineficaz a la prueba anticipada en el delito de indemnidad sexual específicamente en la declaración que brinda la victima mediante su solicitud por las partes legitimadas. Investigación de tipo mixto con un diseño observacional no experimental y con nivel descriptivo. La muestra intencional estuvo conformada por 67 abogados y por 2 fiscales en la cual fueron entrevistados mediante la guía de entrevista semi estructurada. A las principales conclusiones es que hubo divergencia de consideraciones por parte de abogados y fiscales. Los fiscales consideran que debería modificarse el articulo 242 a fin de que haya una actualización. La no utilización de la norma procesal penal y la estrategia fiscal y defensa sobre la teoría del caso son los principales factores influyentes.
\end{abstract}

Palabras claves: Prueba anticipada, Indemnidad sexual, Teoría del caso y menor de edad.

\begin{abstract}
Investigation developed with the purpose of knowing which are the main factors that render ineffective the anticipated proof in the crime of sexual indemnity specifically in the declaration that the victim offers through his request by the legitimate parties. Mixed type research with a nonexperimental observational design and a descriptive level. The intentional sample was made up of 67 lawyers and 2 prosecutors in which they were
\end{abstract}

\footnotetext{
${ }^{1}$ Maestro en Derecho con mención en Ciencias Penales por la Universidad Privada de Tacna. henryd218@hotmail.com. ORCID: 0000-0001-5676-6417

2 Doctor en Derecho, Gerente General del estudio Soza y Asociación SAC. Académico de la Escuela de Postgrado de la Universidad Privada de Tacna. hsoza5@hotmail.com. ORCID: 0000-0002-9103-9423
} 
interviewed using the semi-structured interview guide. To the main conclusions is that there was a divergence of considerations on the part of lawyers and prosecutors. Prosecutors believe that Article 242 should be amended in order for there to be an update. The non-use of the criminal procedural rule and the fiscal and defense strategy on the theory of the case are the main influencing factors.

Key words: Early test, sexual indemnity, Case theory and minor.

\section{INTRODUCCIÓN}

La prueba anticipada en el delito de indemnidad sexual es una forma de protección de la declaración primigenia de la víctima menor de edad y de su integridad psicológica y emocional, pero también para identificar de porque es escasa la solitud por parte de los legitimados la prueba anticipada al juez de la investigación preparatoria y cuáles son esos factores que vuelven ineficaz a la prueba anticipada, ya que en este tipo delitos se mantiene estable y va en aumento según las estadísticas dadas por los noticieros y el observatorio criminal del Ministerio Publico, mayormente dichos delitos ocurren en el ámbito de la clandestinidad y ocultamiento, como también en el círculo familiar donde integran los padres, hermanos, primos o padrastros, y analizando esta situación es que puede ser factible de que se manipule la declaración de la menor y se corre el alto riesgo de que se contamine por influencias familiares o amigos de la familia, en ese contexto es necesario señalar que, la declaración que brinda la víctima durante los actos de investigación si bien es cierto es protegida y bien llevada por los profesionales capacitados y altamente especializados llevándose a cabo en un ambiente adecuado con el uso de la cámara gesell, con los requerimientos que exige la guía de procedimiento para la entrevista única. Es cierto que sin la necesidad de que se solicite la prueba anticipada para la declaración de la víctima es bien llevada, con el apoyo de la unidad de protección y asistencia de víctimas y testigos, pero como bien se sabe siempre es más fácil manipular la declaración de un niño que un adulto y encontrar la mentira de un niño que de un adulto. En esa misma línea, no se busca de que en todos los casos de indemnidad sexual se solicite y utilice la prueba anticipada, lo que se pretende es que hay casos excepcionales que pueden emerger desde las primeras diligencias de actos de investigación, la necesidad de solicitar dicha prueba ya que se ha vuelto una costumbre común de que la declaración de la víctima se ha practicada como un acto de investigación y no como un acto de prueba.

Hoy en día es habitual escuchar y leer las fuentes de información, la cantidad de casos de violación sexual a menores de edad, ante la constante estabilidad de este delito hacia los menores y las consecuencias que trae el delito mencionado, que en su agravio sufren victimización primaria y luego podría ser que se dé la figura de la revictimización que acarrea la víctima, sufrimiento que se da por parte de los operadores de justicia y especialmente durante la investigación que se realiza en este delito, la victima menor de edad es el sujeto pasivo de este hecho delictivo como también titular del bien jurídico protegido como es la "Libertad e Indemnidad sexual", también es necesario mencionar que a la vez la víctima se convierte directamente en el objeto de la acción justamente donde recae la acción típica que 
realiza el sujeto activo, entonces la víctima en esta clase delitos se convierte en el sujeto pasivo del bien jurídico protegido y sujeto pasivo de la acción típica.

En el Perú mediante Decreto Legislativo N 957 con fecha 29 de julio del año 2004 se promulgo el Nuevo Código Procesal Penal, que luego durante el transcurso de los años fue entrando en vigencia en distintas regiones del país, aquí en la ciudad de Tacna entro en vigencia en el año 2008. En el nuevo modelo procesal penal el fiscal se convierte en director y conductor de la investigación preparatoria esta incluye las diligencias preliminares, realiza los actos de investigación con apoyo principal de la policía nacional de Perú y demás instituciones, en la etapa intermedia luego de haber concluido la investigación preparatoria, es en donde el fiscal luego de juntar los elementos de cargo y descargo tiene que decidir si formula el requerimiento de acusación o realiza el requerimiento de sobreseimiento si el fiscal presenta un requerimiento de acusación tiene que acompañar con los medios de prueba que reunió durante los actos de investigación para que puedan actuarse en la etapa de juzgamiento, en la etapa de juzgamiento que es la última fase se practican los actos de prueba que se producen o presentan en dicha etapa que estarán bajos los principios de publicidad, inmediación, oralidad y contradicción, actos de prueba que tendrán como finalidad crear convicción y certeza en juez penal unipersonal o colegiado serán estos actos de prueba que servirán como fundamento para dar un sentencia condenatoria o absolutoria.

Es necesario mencionar en el Nuevo Código Procesal Penal en su artículo 242 modificado por el artículo 2 del (Decreto Legislativo $N^{\circ}$ 1307, 2016) de fecha 30 de diciembre del 2016, que señala textualmente "Durante las diligencias preliminares o una vez formalizada la investigación preparatoria, a solicitud del fiscal o de los demás sujetos procesales, podrá instarse al juez de la investigación preparatoria la actuación de una prueba anticipada, en los siguientes casos (...) Declaración de las niñas, niños y adolescentes en su calidad de agraviados por delitos comprendidos en los artículos 153 - 153-A del capítulo I: Violación de la libertad personal, y en los comprendidos en el capítulo IX: Violación de la libertad sexual, capitulo X: proxenetismo y capitulo XI: ofensas al pudor público, correspondientes al título IV: Delitos contra la Libertad, del código penal".

"Las declaraciones de las niñas, niños y adolescentes serán realizadas con la intervención de psicólogos especializados en cámaras Gesell o salas de entrevistas implementadas por el ministerio público". Las declaraciones y entrevistas serán filmadas y grabadas a fin de evitar la revictimización de los agraviados" (Nuevo código procesal penal, 2018, Art. 242)

Es necesario mencionar el protocolo sobre la constitución de la declaración única a víctimas de violencia sexual en prueba anticipada - Junín que a la letra resalta "El / La fiscal solicita al Juez/a de Investigación Preparatoria que se lleve a cabo la audiencia de prueba anticipada en el momento en el que tome conocimiento de la denuncia, sin dilaciones, ni aplazamientos, directamente o a través de la Policía...”. (García, 2015).

Sobre el protocolo que se destaca de la Corte Superior de Justicia de Junín, es de bastante importancia al tratar de asegurar la versión primigenia que brinda la víctima en los casos de delitos de violación a la indemnidad sexual cuando los hechos ocurren especialmente dentro del ámbito familiar, porque se podría correr el riesgo desde los primeros instantes que se denuncia el delito antes señalado la víctima por el impacto psicológico que trae consigo el hecho delictivo se retracte o por las presiones familiares o como lo menciona claramente Gabriel Vitale, 2007, "en cuanto a la cuestión de la retractación, esta es definida como parte 
del denominado Síndrome de acomodación del abuso sexual infantil, este síndrome contempla que es habitual que el niño se vea presionado por sus sentimientos de culpa y por el sufrimiento de sus familiares, y sienta que tiene en su poder la responsabilidad de proteger o dañar a su familia" citado por (Tapia Vargas, 2017, Pág.10). Entonces en este tipo de casos sería viable solicitar la declaración de la víctima del delito de indemnidad sexual como prueba anticipada porque podría correr el riesgo de que la víctima se retracte por creer que en su poder se encuentra pendiente la integridad familiar y dejar impune el delito de violación a la indemnidad sexual, si bien es cierto como se señaló anteriormente que el sistema penal promueve y fomenta la declaración única que brinda la víctima y esto se da mediante el procedimiento de la entrevista única utilizando la herramienta forense legal como la cámara gesell con las directivas y protocolos establecidos por el ministerio público, esto quiere decir que ya la víctima no volvería a declarar en el procedimiento de la investigación.

Es menester mencionar, que el (Acuerdo Plenario $N^{\circ} 01-2011$ ) sobre "apreciación de la prueba en los delitos contra la libertad sexual" específicamente en su fundamento 38 establece la posibilidad excepcional por parte del juez de que la víctima menor de edad de violación sexual declare en la fase estelar del juicio oral, el acuerdo plenario antes señalado es destacado específicamente su fundamento 38 por la Casación №33 - 2014 Ucayali y también por el Recurso de Nulidad $N^{\circ} 3303$ - 2015, entonces haciendo un análisis la declaración única que brinda la víctima del delito de indemnidad sexual podría ser que no satisfaga o sea insuficiente para la investigación penal porque el juez decisor, tiene la posibilidad de que llame a la víctima para que sea examinada en el juicio oral y así vuelva a declarar la misma. Blanco Martínez, Buenahora Remolina, Gómez López, 2013, pretende estudiar la viabilidad de la prueba anticipada en los delitos sexuales de menores de catorce años, conocer su importancia en pro de evitar la revictimización de los menores abusados sexualmente, así como establecer si en su práctica existe vulneración en los derechos al debido proceso y al derecho de defensa del indiciado o acusado. El "Diseño Procesal y Actores Procesales" si contribuyen a la revictimización o victimización secundaria en los menores de edad agraviados del delito de violación sexual (Lingan Cabrera, 2015). Cuando la sindicación de la víctima es uniforme y existen pruebas suficientes de culpabilidad la sentencia siempre es condenatoria, como también se confirma la segunda hipótesis planteada donde el juzgador fundamenta sus decisiones en pruebas directas pericias, reconocimiento médico legal, aceptación del inculpado y obviando en tomar consideración las pruebas indirectas o indiciaria (Choque Valenzuela, 2015). La declaración de la víctima para pueda crear certeza o convicción en el juez para que así haya una sentencia (Lara Cueva, 2017)

\section{OBJETIVOS}

- Determinar en qué medida la adecuada utilización de la norma procesal penal y la adecuada estrategia fiscal y defensa sobre la teoría del caso, contribuirían a la adecuada utilización de la declaración de la víctima como prueba anticipada, Tacna - 2017.

- Determinar En qué medida la ineficacia de norma procesal penal que faculta solicitar declaración de las víctimas del delito indemnidad sexual como prueba anticipada, obligaría a modificarla, Tacna - 2017 


\section{METODOLOGÍA}

Enfoque metodológico mixto, nivel descriptivo. El ámbito de la investigación es en el distrito de Tacna y tiempo social hemos tomado en consideración el año 2017. En la presente investigación se cuenta con dos unidades, la primera está conformada por Abogados $(n=67)$ y la segunda por Fiscales en el ámbito penal.

\section{RESULTADOS}

\section{Tabla 1 Encuestas realizadas a los abogados}

\begin{tabular}{|c|c|c|c|c|}
\hline & \multicolumn{2}{|c|}{$\mathrm{SI}$} & \multicolumn{2}{|c|}{ NO } \\
\hline & $\mathrm{n}$ & $\%$ & $\mathrm{n}$ & $\%$ \\
\hline $\begin{array}{l}\text { ¿Usted, tenía conocimiento de la modificación que se dio del Artículo } 242 \text { del Nuevo } \\
\text { Código Procesal Penal con el Decreto Legislativo } N^{\circ} 1307 \text { en el año } 2016 \text { sobre supuestos } \\
\text { de prueba anticipada? }\end{array}$ & 47 & 70,1 & $\underline{20}$ & 29,9 \\
\hline $\begin{array}{l}\text { ¿Considera usted, que hay principales factores asociados que hacen ineficaz para solicitar } \\
\text { la declaración de la víctima del delito de indemnidad sexual como prueba anticipada } \\
\text { durante las diligencias preliminares? }\end{array}$ & 53 & 79,1 & 14 & 20,9 \\
\hline $\begin{array}{l}\text { ¿Conoce usted, principales factores que si determinarían que el fiscal o demás sujetos } \\
\text { procesales soliciten la declaración de la víctima del delito de indemnidad sexual sea } \\
\text { actuada como prueba anticipada durante las diligencias preliminares? }\end{array}$ & 43 & 64,2 & 22 & 32,8 \\
\hline $\begin{array}{l}\text { ¿Considera usted, que el factor desconocimiento de la norma procesal influye en la no } \\
\text { solicitud de la declaración de la víctima de delito de indemnidad sexual como prueba } \\
\text { anticipada por parte del Fiscal y de los demás sujetos procesales? }\end{array}$ & 59 & 88,1 & 7 & 10,4 \\
\hline $\begin{array}{l}\text { ¿Considera usted, que el factor estrategia de teoría del caso influye en la no solicitud de } \\
\text { la declaración de la víctima del delito de indemnidad sexual como prueba anticipada por } \\
\text { parte del Fiscal y de los demás sujetos procesales? }\end{array}$ & 38 & 56,7 & 28 & 41,8 \\
\hline $\begin{array}{l}\text { ¿Considera usted, que el factor circunstancias propia de la víctima influye en la no } \\
\text { solicitud de la declaración de la víctima del delito de indemnidad sexual como prueba } \\
\text { anticipada por parte del Fiscal y de los demás sujetos procesales? }\end{array}$ & 50 & 74,6 & 16 & 23,9 \\
\hline $\begin{array}{l}\text { ¿Considera usted, con la nueva descripción del Artículo } 242 \text { del Nuevo Código Procesal } \\
\text { Penal para la solicitud de declaración de la víctima del delito de indemnidad sexual } \\
\text { como prueba anticipada es opcional y no obligatoria? }\end{array}$ & 44 & 65,7 & 22 & 32,8 \\
\hline $\begin{array}{l}\text { ¿Considera usted que hay un criterio unificado a la hora de interpretar el diseño } \\
\text { procesal sobre supuestos de prueba anticipada exactamente el inciso D de la } \\
\text { declaración de la víctima del delito de indemnidad sexual durante las diligencias } \\
\text { preliminares, por parte de los jueces, fiscales y abogados? }\end{array}$ & 29 & 43,3 & 35 & 52,2 \\
\hline $\begin{array}{l}\text { ¿Usted tiene conocimiento o alguna experiencia de haber solicitado en la declaración } \\
\text { de la víctima de delito de indemnidad sexual para que sea actuada como prueba } \\
\text { anticipada durante las diligencias preliminares? }\end{array}$ & 16 & 23,9 & 51 & 76,1 \\
\hline $\begin{array}{l}\text { ¿Considera usted, que la ineficacia del instituto procesal penal que faculta para solicitar } \\
\text { la declaración de las víctimas del delito de indemnidad sexual como prueba anticipada } \\
\text { durante las diligencias preliminares o una vez formalizada la investigación preparatoria } \\
\text { según el Artículo } 242 \text { del NCPP, se tendría que modificar para mayor esclarecimiento? }\end{array}$ & 55 & 82,1 & 10 & 14,9 \\
\hline $\begin{array}{l}\text { ¿Usted considera, en la declaración que brinda la víctima en el delito de indemnidad } \\
\text { sexual actuada como prueba anticipada mediante la solitud se aseguraría plenamente a } \\
\text { que la víctima declare una sola vez como aseguramiento de una fuente de prueba? }\end{array}$ & 48 & 71,6 & 19 & 28,4 \\
\hline $\begin{array}{l}\text { ¿propondría usted, según el diseño procesal del Articulo } 242 \text { del Nuevo Código Procesal } \\
\text { Penal que se especifique claramente que casos de delitos de indemnidad sexual en la } \\
\text { declaración de la víctima se tendría que solicitar de manera obligatoria la actuación del } \\
\text { instituto jurídico de la prueba anticipada? }\end{array}$ & 54 & 80,6 & 12 & 17,9 \\
\hline $\begin{array}{l}\text { ¿ propondría usted, en los casos de delitos contra la indemnidad sexual donde el agresor } \\
\text { fuera un familiar de la víctima, se tendría que actuar la prueba anticipada durante las } \\
\text { diligencias preliminares en la declaración que brinda la misma de manera obligatoria a } \\
\text { fin de que no sea contaminada o variada por presiones familiares para asegurar la } \\
\text { fuente de prueba de la versión primigenia? }\end{array}$ & 60 & 89,6 & 6 & 9,0 \\
\hline
\end{tabular}




\section{DISCUSIÓN}

La adecuada utilización de la norma procesal penal y la adecuada estrategia fiscal y defensa sobre la teoría del caso, en medida eficaz contribuirían a la adecuada utilización de la declaración de la víctima como prueba anticipada a fin de evitar su revictimización. Hay una tendencia de que la mayoría de abogados encuestados consideran que, con la debida utilización de la norma procesal específicamente en su artículo 242 habrá un buen uso de la declaración de la víctima de violación de indemnidad sexual como prueba anticipada, es más aseguran la mayoría de abogados que, con la adecuada utilización de la norma procesal habrá un buen uso de la prueba anticipada en los casos de indemnidad sexual cuando el agresor sea una persona muy cercana a la víctima de dicho delito, por lo tanto consideramos que si contribuirán en medida eficaz la adecuada utilización de la norma procesal. La mayoría de abogados consideran que la estrategia sobre la teoría del caso influye en la no solicitud de la prueba anticipada en el delito de indemnidad sexual, entonces diríamos que la adecuada estrategia de teoría del caso no influye en medida eficaz en la adecuada utilización de la prueba anticipada. Por otro lado, como un valor agregado tenemos a las entrevistas semi estructuradas realizadas a los Fiscales, en la que manifiestan que con la estrategia de la teoría del caso si hay una debida utilización de la declaración de la víctima como prueba anticipada, además complementar de las entrevistas realizadas hay una medida eficaz de la estrategia de la teoría del caso para la debida utilización. Los fiscales consideran que, si debería modificarse dicho diseño procesal de la prueba anticipada en el delito de indemnidad sexual, a fin de que haya una actualización y mayor esclarecimiento para su debida utilización en los casos pertinentes, a la vez consideramos que hay una medida alta para la modificación del artículo 242 del Nuevo Código Procesal Penal. Misma idea comparten los abogados encuestados donde manifiestan la mayoría de que debería modificarse para mayor esclarecimiento a fin de actualizarla. Tanto la no utilización de la norma procesal penal y la estrategia fiscal y defensa sobre la teoría del caso, son los principales factores de ineficacia de norma procesal penal que faculta solicitar como prueba anticipada declaración de víctimas del delito indemnidad sexual, y en esa misma línea de ideas para los abogados la estrategia sobre la teoría del caso es un principal factor que vuelve ineficaz a la prueba anticipada en el delito de indemnidad sexual. Se pudo determinar que con la adecuada utilización de la norma procesal penal si contribuiría en medida alta a la adecuada utilización de la declaración de la víctima como prueba anticipada, en esa misma línea no se diría lo mismo sobre la adecuada estrategia fiscal y defensa sobre la teoría del caso, ya que por parte del Fiscal se estaría contribuyendo en medida alta la teoría del caso y por parte del Abogado en medida baja dicha teoría para la adecuada utilización de la declaración de la víctima como prueba anticipada. Hay una opinión unida tanto de Fiscales y Abogados en el punto que hay un contraste de demasía del uso de la prueba anticipada en ciertos casos específicos, ante el reconocimiento de los especialistas del derecho antes citados y los resultados consignados, se puede determinar que hay un nivel alto de que debería modificarse el artículo 242 del Nuevo Código Procesal Penal a fin de que haya una actualización y esclarecimiento, por ultimo mencionar que durante el análisis de los resultados no se pudo verificar de que haya un mayor porcentaje por parte del fiscal y abogado una experiencia propia en la utilización de la prueba anticipada en el delito de indemnidad sexual. Se recomienda que se modifique el 242 del Nuevo Código Procesal penal, y se establezcan en qué circunstancias particulares de casos de delitos indemnidad sexual, se tendría que actuar de manera inmediata la prueba anticipada para que también haya un mayor esclarecimiento para su buen uso de dicha figura. Los Fiscales y Abogados como representantes de la sociedad 
y sujetos procesales, son los más aptos en solicitar la figura procesal de la prueba anticipada según la norma, de que unifiquen criterios y experiencias respecto en el momento que se está practicando la declaración de la víctima en cámara gesell como prueba anticipada. A la fiscalía se recomienda que en estos tipos de casos de indemnidad sexual se investigue más a fondo, sobre el estado y comportamiento de la víctima de dicho delito porque es necesario señalar que las victimas menores de edad son las que sufren directamente las consecuencias nocivas que trae el delito de indemnidad sexual.

\section{REFERENCIAS BIBLIOGRÁFICAS}

2011, A. P. (06 de Diciembre de 2011). Obtenido de www.derecho.usmp.edu.pe/cedp/jurisprudencia/Acuerdo\%20Plenario\%20N1_2011.pdf

30076, L. (19 de 08 de 2013). http://busquedas.elperuano.com.pe/normaslegales/ley-que-modificael-codigo-penal-codigo-procesal-penal-cod-ley-n-30076-976387-1/. Recuperado el 09 de 08 de 2017, de http://busquedas.elperuano.com.pe/normaslegales/ley-que-modifica-el-codigopenal-codigo-procesal-penal-cod-ley-n-30076-976387-1/

Blanco Martínez, Buenahora Remolina \& Gómez López. (2013). Viabilidad de la práctica de la prueba anticipada testimonial en víctimas de delitos contra la libertad, integridad y formación sexual en menores de catorce años. Universidad Libre de Colombia, Bogotá - Colombia. Recuperado de

http://repository.unilibre.edu.co/bitstream/handle/10901/7541/BlancoMartinezLuisJose2013. pdf?sequence $=1$

Cabrera, L. M. (Noviembre de 2015). Factores juridicos que influyen en la victimizacion secundaria en menores de edad agraviados por violacion sexual en la aplicacion del codigo procesal penal peruano 2004 en el distrito judicial de cajamarca 2011 - 2014. Universidad Privada Antonio Guillermo Urrelo, Cajamarca, Peru. Recuperado de http://repositorio.upagu.edu.pe/bitstream/handle/UPAGU/144/DP\%20\%20016\%20TESIS\%20LUIS\%20LING\%C3\%81N.pdf?sequence=1\&isAllowed=y

Corte Suprema de Justicia, Sala Penal permanente. (28 de octubre del 2015) Casación N³3-2014. (MP José Neyra)

Corte Suprema de Justicia de la Republica, Segunda Sala Penal Transitoria. (24 de febrero del 2017) Recurso de Nulidad N 3303-2015. (MP Cesar Hinostroza).

Corte Suprema de Justicia de la Republica, Las Salas penales Permanentes y transitorias. (11 de octubre del 2017) Sentencia Plenaria Casatoria N 1-2017. (MP Prado Saldarriaga \& Neyra Flores).

Corte Superior de Justicia de Tumbes, Primer Juzgado de Investigación Preparatoria. (26 de enero del 2018) Resolución $N^{\circ}$ 03. (Juan Carlo Valdivieso Gonzales)

Choque Valenzuela, E. (2015). Valoración de la prueba en los delitos de violación sexual en agravio de los menores de edad en el distrito judicial del cusco 2011-2012. Universidad Andina Néstor Cáceres Velásquez, Juliaca - Perú. Recuperado de http://repositorio.uancv.edu.pe/bitstream/handle/UANCV/349/P29003. pdf? sequence=1\&isAllowed $=y$

Del Código de Procedimiento Penales al Nuevo Código Procesal Penal, (S.F). Recuperado de http://historico.pj.gob.pe/CorteSuperior/noticias/..\%5C..\%5Ccortesuperior\%5CHuaura\%5Cdoc umentos\%5CCapitulo\%201\%20NCPP.pdf

Decreto Legislativo, Decreto Legislativo que modifica la ley $N^{\circ} 30364$, ley para prevenir, sancionar y erradicar la violencia contra las mujeres y los integrantes del grupo familiar. (04 de setiembre del 2018). Recuperado de https://busquedas.elperuano.pe/download/url/decreto-legislativoque-modifica-la-ley-n-30364-ley-para-p-decreto-legislativo-n-1386-1687393-4 
Docs.peru.justia. (05 de 06 de 2001). http://docs.peru.justia.com/federales/leyes/27472-jun-42001.pdf. Recuperado el 09 de 08 de 2017, de http://docs.peru.justia.com/federales/leyes/27472-jun-4-2001.pdf

docs.peru.justia.com. (28 de 09 de 1994). http://docs.peru.justia.com/federales/leyes/26357-sep-231994.pdf. Recuperado el 09 de 08 de 2017, de http://docs.peru.justia.com/federales/leyes/26357-sep-23-1994.pdf

Facultad de Ciencias Empresariales, FACEM (2014). Protocolo de Investigación de la Facultad de Ciencias Empresariales. Tacna - Perú: Universidad Privada de Tacna - recuperado de http://www.upt.edu.pe/upt/sgc/assets/ckeditor/kcfinder/upload/files/PROTOCOLO\%20DE\%2 OINVESTIGACION\%202016\%281\%29.pdf

García, M. Y. (2015). Protocolo sobre la constitución de declaración única a victimas de violencia sexual en prueba anticipada - junin. 05. Recuperado de https://www.demus.org.pe/wpcontent/uploads/2016/05/Protocolo-PJ-Junin.pdf

Jurista Editores. (2018). Código Penal - Lima - Perú: Editorial - Jurista Editores E.I.R.L

Lara Cueva, D. J. (2017). Eficacia del valor probatorio de la declaracion de la victima en el delito de violacion sexual de menor de catorce años de edad en los juzgados penales de la corte superior de justicia del santa 2015 - 2016. Universidad Cesar vallejo, Nuevo Chimbote, Peru. Recuperado de http://repositorio.ucv.edu.pe/bitstream/handle/UCV/12618/lara_cd.pdf?sequence=1\&isAllow ed $=y$

Lexus, (1996). Lexus Diccionario Enciclopédico. Barcelona - España: Editorial el Trébol S.L

Neyra Flores, J.A, (2010). Manual de Nuevo Proceso Penal \& de Litigación Oral. Recuperado de http://www.derecho.usmp.edu.pe/postgrado/maestrias/maestria_ciencias_penales/cursos/4c iclo/PENAL_IV_JUICIO_Y_PROCESOS_ESPECIALES/neyra_flores/MAN_NUE_PRO_PE-LIT_OR.pdf MIMP. (31 de 07 de 2017). http://www.mimp.gob.pe/contigo/contenidos/pncontigoarticulos.php?codigo=33. Recuperado el 2017 de 08 de 01, de http://www.mimp.gob.pe/contigo/contenidos/pncontigo-articulos.php?codigo=33

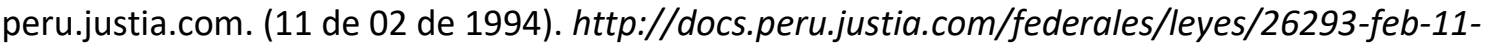
1994.pdf. Recuperado el 09 de 08 de 2017, de http://docs.peru.justia.com/federales/leyes/26293-feb-11-1994.pdf

Republica, L. (26 de abril de 2017). Obtenido de https://larepublica.pe/sociedad/1035525-peru-es-elsegundo-pais-con-mayor-violencia-sexual

SantaCruz Morales \& SantaCruz Fernández, (2015). La Importancia de la Teoría del Caso para Lograr una Defensa Adecuada.

Tapia Vivas, (2017). La valoración de la prueba en el delito de violación sexual de menores de edad. En Tapia Vivas, Villegas Paiva, Rodriguez Champi \& Arismendiz Amaya (coord.), Como probar el delito de violación de menores (Pág.10), Lima - Perú: El Búho E.I.R.L

Trabajo, O. I. (17 de 05 de 1999).

http://www.ilo.org/dyn/natlex/natlex4.detail?p_lang $=e s \& p \_i s n=53479 \& p \_c o u n t r y=P E R \& p \_c o$ unt $=1424 \& p \_$classification=01.04\&p_classcount=98. Recuperado el 09 de 08 de 2017, de http://www.ilo.org/dyn/natlex/natlex4.detail?p_lang=es\&p_isn=53479\&p_country=PER\&p_co unt $=1424 \& p \_c l a s s i f i c a t i o n=01.04 \& p \_c l a s s c o u n t=98$

UNODC, R. (2014). Obtenido de https://www.unodc.org/documents/ropan/Technical_Consultative_Opinions_2014/OTC_001_ 2014.pdf

Villegas Paiva, E.A (2013). El agraviado y la reparacion civil en el Nuevo Codigo Procesal Penal. Lima: El Buho E.I.R.L.

Wordpress. (19 de 09 de 2015). https://violenciaenlasfamilias.wordpress.com/2015/09/19/elsindrome-de-acomodacion-de-roland-summit/. Recuperado el 02 de 08 de 2017, de https://violenciaenlasfamilias.wordpress.com/2015/09/19/el-sindrome-de-acomodacion-deroland-summit/ 